\title{
TRICHOPHAGIA AND TRICHOBEZOAR IN A 12 YEAR OLD GIRL: A CASE REPORT
}

Kumar Premjeet Madhukar ${ }^{1}$, Devendra Taide², Radha Verma ${ }^{3}$, Manjusha Sailukar ${ }^{4}$, Zaffar Sayed ${ }^{5}$

\section{HOW TO CITE THIS ARTICLE:}

Kumar Premjeet Madhukar, Devendra Taide, Radha Verma, Manjusha Sailukar, Zaffar Sayed. "Trichophagia and Trichobezoar in a 12 year Old Girl: A Case Report". Journal of Evolution of Medical and Dental Sciences 2014; Vol. 3, Issue 25, June 23; Page: 6928-6931, DOI: 10.14260/jemds/2014/2841

\begin{abstract}
Trichobezoar consists of a compact mass of hair occupying the gastric cavity to a various extent. When the trichobezoar extends past the duodenum it is better referred to as Rapunzel syndrome. They occur in emotionally disturbed, depressed, or mentally retarded patients who have trichotillomania and trichophagia. It is almost exclusively seen in girls. An underlying functional or mechanical obstruction of the gastrointestinal tract (after gastric surgery, gastric dysmotility, for example) may predispose to bezoar formation in rare instances. Although trichobezoars are well described in terms of surgical diagnostic and procedure, there are only but very scarce reports on psychiatric literature, usually associated with trichotillomania. We present a clinical case of trichobezoar in a 12 year old female and discuss the most relevant aspects concerning this entity.
\end{abstract}

KEYWORDS: Bezoar, Trichobezoar, Trichotillomania, Trichophagia.

INTRODUCTION: Bezoar is a tightly packed collection of undigested material that is unable to exit the stomach. Most bezoars are of indigestible organic matter such as hair - trichobezoars; or vegetable and fruit the - phytobezoars; or a combination of both but other rare substances has been also been described in literature. The most frequent type of bezoar in adults is phytobezoar, while trichobezoars are more often found in children and teenage girls ${ }^{1}$. Trichobezoars, commonly occur in patients with psychiatric disturbances who chew and swallow their own hair.

Only 50\% will have history of trichophagia and usually they occur in emotionally disturbed, depressed or mentally retarded. Trichobezoars have been described in literature and they comprise $55 \%$ of all bezoars. In very rare cases the Rapunzel Syndrome hair extends through the pylorus into the small bowel causing symptom and sign of partial or complete gastric outlet obstruction ${ }^{2}$. Although trichobezoars are well described in terms of surgical diagnosis and procedure, there are only but scarce reports on psychiatric literature. This case report describes the case of a 12 years old female patient diagnosed with a trichobezoar who had a history of eating scalp hair for 5 years.

CASE REPORT: A 12 year old girl presented to surgical OPD with abdominal lump for 3 years and dull aching pain for 1 year with history of weight loss. Her physical examination revealed the presence of a large, hard, solid mass from epigastric to periumbilical region, mobile and painless with no other remarkable features. An abdominal ultra-sound revealed a highly reflective structure not allowing in-depth evaluation. Barium meal follow through suggested a huge mass in the stomach probably a trichobezoar [Fig. 1]. On counseling the patient and her family revealed the history of eating scalp hair for 5 years. An anterior gastrotomy with removal of bezoar was done which revealed the presence of human hair [Fig. 2]. The patient was counseled by psychiatrist and medicated with fluoxetine $20 \mathrm{mg}$ and risperidone $0.5 \mathrm{mg}$, showing "mild improvement" in such episodes. 
DISCUSSION: Trichobezoars were first described by Baudomant in 17793,4, consisting of a compact mass of hair, occupying the gastric cavity to a various extent. The term "bezoar" is thought to be derived from the Arabic word for antidote - "bazahr" or "badzehr", because stones obtained from the stomach or intestines of animals were thought to have medicinal properties. . $^{4-6}$

Bezoars can be classified in four types: phytobezoar (vegetable); trichobezoar (hair); lactobezoar (milk/curd) and miscellaneous (fungus, sand, paper, etc). ${ }^{6}$ They are usually found in the stomach, but they may also be found in the duodenum and other parts of the intestine..$^{5-7}$ The most frequent type of bezoar in adults is phytobezoar, while trichobezoars are more often found in children and teenage girls. ${ }^{2}$

The pathogenesis of bezoars is not consensual. It is believed that the smooth surface of hair does not allow for its propagation through peristalsis, getting trapped in the mucosa. ${ }^{2}$ However, the stomach of normal individuals is able to clear even large foreign bodies in up to 80 to $90 \%$ of the cases, which may imply that bezoar formation occurs in the presence of both altered gastric anatomy or physiology and continued ingestion of the offending substance. ${ }^{8,9}$ When the trichobezoar is seen extending from the stomach to various lengths of the intestine is called "Rapunzel Syndrome", for its resemblance to a tail.10

Majority of cases of trichobezoar present late, due to the low index of suspicion by the physician. Of 131 collected cases of trichobezoar, a palpable abdominal mass was present in (87.7\%), abdominal pain (70.2\%), nausea and vomiting (64.9\%), weakness and weight loss (38.1\%), constipation or diarrhoea (32\%) and hematemesis (6.1\%). The laboratory investigations revealed low hemoglobin in about 62\% (average). ${ }^{11}$ The complications of Rapunzel syndrome ranges from attacks of incomplete pyloric obstruction to complete obstruction of the bowel and rarely perforation, peritonitis and mortality. ${ }^{10}$

During the past 10 years, in their enthusiasm about modern technical developments, several investigators have undertaken the treatment of large gastric trichobezoars in a so-called minimally invasive manner. The first group ${ }^{12}$ subjected a 14-year-old girl to several endoscopic sessions in which attempts to fragment the bezoar first with a water-pick system, later with an Nd: YAG laser failed; extracorporeal shock wave lithotripsy failed as well. Their conclusion was that nonsurgical methods were of little use and had no place in the treatment of gastric trichobezoar. A second case ${ }^{13}$ was managed by endoscopic removal using three sessions of 2 to 3 hours' duration each, during which it was necessary to pass the endoscope more than a hundred times in all. In a third case, ${ }^{14} \mathrm{a}$ large gastric trichobezoar was fragmented and removed with laparoscopic instrumentation using two large percutaneous gastrotomy ports. Finally, in a fourth case, ${ }^{15}$ a large gastric trichobezoar was removed laparoscopically. A long gastrotomy was made laparoscopically, and the bezoar was placed in a plastic bag and retrieved through a suprapubic laparotomy.

The last three cases have shown that other methods of treatment are possible, but their superiority to the more conventional technique is questionable. In our opinion, the only advantage, if any, is cosmetic. These newer procedures are reported by surgeons to be complex, time-consuming, and tedious.

After careful analysis of these case reports, we conclude that these procedures must be restricted to smaller trichobezoars. For the large formations, open surgery seems to be the preferred method. More important is the need for psychiatric follow-up, which seems essential to diminish the frequency of recurrence. 


\section{REFERENCES:}

1. Frey AS, McKee M, King RA, Martin A. Hair apparent: Rapunzel syndrome. Am J Psychiatry. 2005; 162: 2. [PubMed]

2. Phillips MR, Zaheer S, Drugas GT. Gastric trichobezoar: case report and literature review. Mayo Clin Proc 1998, 73: 653-656. [PubMed Abstract]

3. Malpani A, Ramani SK, Wolverson MK. Role of sonography in trichobezoars. J Ultrasound Med. 1988; 7: 661-3. [PubMed]

4. Shorter E. A historical dictionary of psychiatry. New York: Oxford University Press; 2005.

5. Bouwer C, Stein DJ. Trichobezoars in trichotillomania: Case report and literature overview. Psychosom Med. 1998; 60: 658-60. [PubMed]

6. Williams RS. The fascinating history of bezoars. Med J Aust. 1986; 145: 613-4. [PubMed]

7. DeBakey M, Ochsner W. Bezoars and concretions: A comprehensive review of the literature with an analysis of 303 collected cases and a presentation of 8 additional cases. Surgery. 1939; 5: 132-60.

8. Coulter R, Antony MT, Bhuta P, Memon MA. Large gastric trichobezoar in a normal healthy woman: Case report and review of pertinent literature. Southern Med J. 2005; 98: 10. [PubMed]

9. Lee J. Bezoars and foreign bodies of the stomach. Gastrointest Endosc Clin N Am. 1996; 6: 60519. [PubMed]

10. Pérez E, Sántana JR, García G, et al. Perforación gástrica en adulto por tricobezoar (síndrome de Rapunzel) Cir Esp. 2005; 78(4): 268-70. [PubMed]

11. Gupta NaikS, Naik S, Chaudhary AK, Jain P, Sharma A: Rapunzel Syndrome Reviewed and Redefined. Dig Surg 2007, 24: 157-161. PubMed Abstract

12. Van Gossum A, Delhaye M, Cremer M. Failure of non-surgical procedures to treat gastric trichobezoar. Endoscopy 1989; 21: 113.

13. Soehendra N. Endoscopic removal of a trichobezoar. Endoscopy 1989; 211: 201.

14. Filipi CJ, Perdikis G, Hinder RA, DeMeester TR, Fitzgibbons RJ, Peters J. An intraluminal surgical approach to the management of gastric bezoars. Surg Endosc 1995; 9: 831-3. PubMed

15. Nirasawa Y, Mori T, Ito Y, Tanaka H, Seki N, Atomi Y. Laparoscopic removal of a large gastric trichobezoar. J Pediatr Surg 1998; 33: 663-5. PubMed.

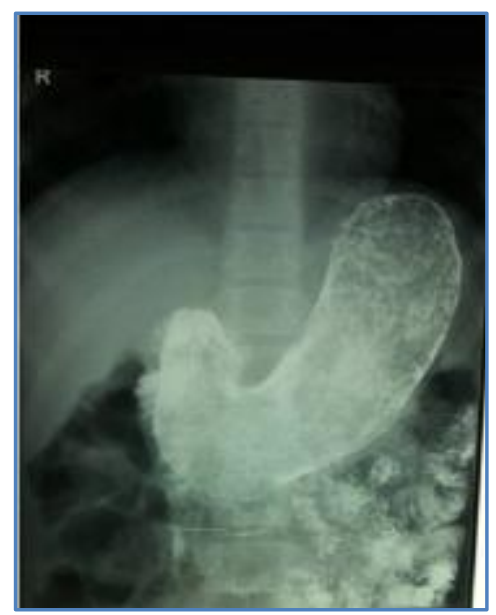

Fig. 1: Barium meal follow through suggestive of a huge mass (trichobezoar) in the stomach 


\section{CASE REPORT}

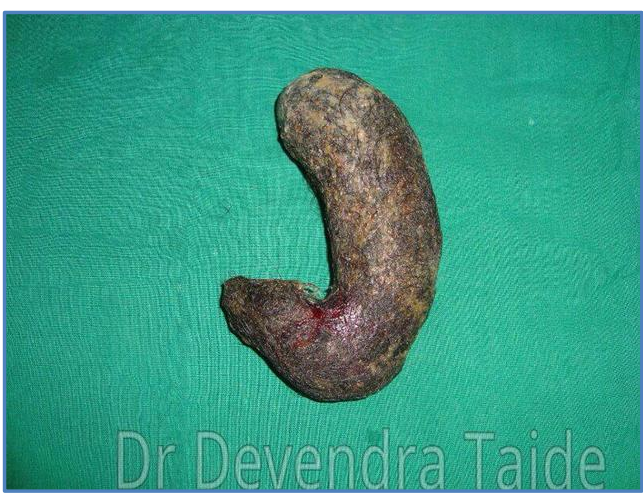

Fig. 2: Specimen of large sized trichobezoar

\section{AUTHORS:}

1. Kumar Premjeet Madhukar

2. Devendra Taide

3. Radha Verma

4. Manjusha Sailukar

5. Zaffar Sayed

\section{PARTICULARS OF CONTRIBUTORS:}

1. Assistant Professor, Department of Surgery, KJSMC, Mumbai, India.

2. Assistant Professor, Department of Paediatric Surgery, KJSMC, Mumbai, India.

3. Professor, Department of Surgery, KJSMC, Mumbai, India.

4. Assistant Professor, Department of Paediatric Surgery, KJSMC, Mumbai, India.

5. Resident Surgeon, Department of General Surgery, KJSMC, Mumbai, India. 